\title{
JOAQUÍN DE FIORE: LA EDAD DEL ESPÍRITU*
}

\author{
Virgilio Rodríguez \\ Universidad Católica de Valparaiso
}

\begin{abstract}
Resumen: Este ensayo desarrolla la cosmovisión de Joaquín de Fiore, abad que vivió entre los siglos XII y XIII y un autor que hoy puede ser considerado uno de los precursores del impulso utópico en Occidente, al proponer tres edades sucesivas del desarrollo espiritual de la humanidad, con un nítido sentido del progreso entre ellas. En no poca medida, arguye el autor, seguimos viviendo bajo la influencia de esta forma de ver las cosas.

Palabras Clave: utopía, pensamiento utópico, progreso, Joaquín de Fiore.

\section{JOACHIM OF FIORE: THE AGE OF THE SPIRIT}

ABstract: This essay sets forth the worldview of Joachim of Fiore, an abbot who lived between the twelfth and thirteenth centuries and may now be regarded as one of the forerunners of the utopian impulse in the West, as he argued for the existence of three successive ages of spiritual development in humanity, with a clear sense of progress from one to the next. In no small measure, argues the author, we still live under the spell of this way of seeing things.
\end{abstract}

KeYwords: utopia, utopian thought, progress, Joachim of Fiore.

VIRGILIO RodRíGuez. Master of arts y master of philosophy por la Universidad Columbia. Académico del Instituto de Arte de la Universidad Católica de Valparaíso. Poeta y ensayista. Su últimos libros son Ocio y cielo (Santiago, 2004) y Los puentes cortados (Santiago, 2014; Madrid, 2015). Email: virjes@gmail.com.

* Este texto corresponde a una versión revisada de la conferencia expuesta por Virgilio Rodríguez en el seminario "El impulso utópico: La plenitud está más allá", desarrollado en el CEP el 1 de junio de 2016. 
C reo que corresponde hacer la pregunta acerca de las razones por las que pueda interesarnos saber de una doctrina y de un personaje del siglo XII y XIII, en plena Edad Media, tan alejados de nuestra contemporaneidad. La respuesta puede ser inmediata: la teoría de Joaquín de Fiore, y su sentido histórico, es la que más influyó en Occidente hasta la aparición del marxismo, en opinión de un estudioso como Norman Cohn. ${ }^{1}$ Por otra parte, su visión escatológica, considerada desde nuestra perspectiva secularizada, conforma una figura importantísima inserta en el dinamismo de lo que hemos llamado para esta ocasión el impulso utópico, que es el que va configurando una dimensión que paulatinamente se llena con las diversas propuestas utópicas.

El sistema elaborado por Joaquín entrega una novedad para el cristianismo de entonces. Por primera vez se hace presente en la concepción cristiana una expectativa del fin de los tiempos que difiere de la espera pasiva del juicio final o de la esperanza de un milenio de plenitud traído exclusivamente por la Providencia, antes de la consumación temporal y la rendición de cuentas universal. Joaquín, con su doctrina de las tres edades, desarrolla una idea ciertamente anticipatoria para su época: la de una historia de la salvación que se va desplegando evolutivamente y que conlleva en ello un progreso del tiempo.

Esta doctrina se desmarca de la filosofía de la historia de San Agustín, la que por entonces dominaba en la cristiandad. De acuerdo con esta última, el mundo se encontraba en la sexta fase de la historia, la última. San Agustín concebía que habrían siete edades, a semejanza de los siete días de la creación, y que la séptima sería el Sabbath, el inicio, fuera de la historia, de la vida eterna. La sexta edad, en tanto, era la de un seculum senescens, el tiempo de la senilidad de la humanidad. Para San Agustín, con la venida de Cristo ya se había realizado el Reino sobre la Tierra, hecho presente en la presencia de la Iglesia como institución perdurable. Sólo quedaba esperar el final decretado por la Divina Providencia. Es preciso añadir que el precepto de Cristo "A vosotros no os toca conocer el tiempo y el momento que ha fijado el Padre con su autoridad" (Hechos de los apóstoles 1:7), ${ }^{2}$ que es la respuesta que

${ }^{1}$ Norman Cohn, En pos del Milenio. Revolucionarios milenaristas y anarquistas místicos de la Edad Media, trad. de Ramón Alaix Busquets (Madrid: Alianza Universidad, 1985), 107.

${ }^{2}$ Biblia de Jerusalén (Bilbao: Desclée de Brouwer, 1975), 1549. 
da a quienes le preguntan por la fecha del restablecimiento del reino de Israel, es la norma que a su vez se ha aducido para frenar las especulaciones y cálculos respecto del advenimiento del Anticristo y el día del juicio final.

La idea de Joaquín de las tres edades sucesivas, con una última en la que el Espíritu Santo progresa, iniciando una nueva edad histórica, deja así a un lado la visión de San Agustín y desmonta la espera propia de esta concepción, para cambiar su signo de pesimismo terrenal por una especulación más optimista del devenir en el más acá. Norman Cohn puntualiza: "Su idea [de Joaquín] de una tercera edad no podía reconciliarse con la concepción agustiniana de que el Reino de Dios ya se había realizado, hasta donde puede realizarse sobre la Tierra, en el momento en que nació la Iglesia, y que no puede haber ningún milenio que no sea éste". 3

Luego es preciso adelantar que la Doctrina del Espíritu de Joaquín se transformó en el fermento de las mayores revoluciones espirituales que se desarrollaron desde la Edad Media, y que influyó en una buena cantidad de ideas políticas y sociales de nuestro tiempo. En opinión de un especialista como Ernst Benz, "al unir las ideas de progreso y desarrollo con la profecía de la inminente plenitud de la historia de la salvación, Joaquín ha creado el modelo para las utopías religiosas, sociales, políticas y filosóficas de los tiempos modernos". 4

Antes de comenzar una breve descripción de lo esencial del sistema visionario de Joaquín, creo pertinente contar algo de la vida de este personaje.

Joaquín de Fiore nació alrededor de 1135 en Celico, un pueblo de Calabria. Era hijo de un notario. En su juventud, tras abandonar un empleo gubernamental, inició un peregrinaje a Tierra Santa en el año 1167. Jerusalén aún estaba en poder cristiano. A su retorno, Joaquín estuvo algún tiempo como eremita en la proximidad de un monasterio griego en el monte Etna, en Sicilia, para luego volver a su Calabria nativa. Allí fue huésped de la abadía cisterciense de Sambucina y luego inició una actividad como predicador. Para ello, fue ordenado sacerdote.

${ }^{3}$ Cohn, En pos del Milenio, 108.

${ }^{4}$ Ernst Benz. Evolution and Christian Hope: Man's Concept of the Future from the Early Fathers to Teilhard de Chardin (New York: Doubleday and Company, 1966), 42. Traducción propia. 
Se aproximó al monasterio de Corazzo, y siguiendo una inclinación natural, se hizo monje y tomó el hábito en Corazzo en 1171. Al poco tiempo fue elegido abad de esa comunidad. Trató entonces de afiliar Corazzo a la orden cisterciense con el aval de Sambucina, sin éxito. Se encaminó en su intento a la casa matriz de Sambucina, Casamari, que era un importantísimo monasterio en Italia. Tampoco tuvo éxito, pero en su estadía en Casamari recibió una revelación referente al misterio de la Trinidad, y escribió allí el primer libro del Psalterio de diez cuerdas. Permaneció trabajando aquí por un año y medio, tiempo en el que inició los libros Exposición sobre el Apocalipsis y Concordia entre el Nuevo y el Antiguo Testamento, los que junto al citado Psalterio constituyen los textos principales de Joaquín.

En Casamari había experimentado las dos visiones que lo iniciaron en su carrera escritural. La primera sobrevino durante la fiesta de Pascua de Resurrección en 1183. Esa visión le reveló la plenitud y la concordia del Viejo Testamento con el Nuevo, el fundamento de la labor exegética de Joaquín. La segunda visión se produjo en la fiesta de Pentecostés, y con ella se hacen presente las figuras, imágenes simbólicas que ilustran su obra y dan cuenta de sus pensamientos. Esta visión es la que es comentada en el Psalterio.

Joaquín tuvo trato con tres Papas de su época: Lucio III, Urbano III y Clemente III, los que se mostraron interesados en su obra y tuvieron una actitud de consideración hacia él resaltando su condición piadosa. Tuvo también Joaquín un famoso encuentro con el rey Ricardo Corazón de León, quien esperaba tiempo favorable para iniciar su cruzada en Tierra Santa, conquistada ya por Saladino. Esa entrevista dejaba ver la importancia de Joaquín, quien ya era afamado como profeta.

No obstante, Joaquín se iba volviendo paulatinamente insatisfecho con su posición como abad de Corazzo, y necesitaba cada vez más tiempo para desarrollar sus comentarios sobre las Sagradas Escrituras. Es así que en 1186 deja Corazzo y construye un refugio privado para continuar su labor escrita en una localidad llamada Petra Lata. En 1188, sin embargo, Joaquín visita la solitaria llanura Sila en Calabria central, y ya en 1190 establece la fundación de un nuevo monasterio, San Giovanni in Fiore, del que será igualmente abad.

En el desarrollo de su vida monástica, Joaquín había permanecido como una suerte de fugitivo de la orden cisterciense. El Papa Celestino 
III, no obstante, regulariza en 1196 esta situación al reconocer como una orden nueva la de Fiore.

En 1201 nuevamente Joaquín se retira a otro lugar. Esta vez se trata de una pequeña Iglesia cerca de Petrafitta, donde establece su retiro monástico al que nomina San Martino di Giove. Allí, y no en Fiore, muere el 30 de marzo de 1202.

En 1240, el cuerpo de Joaquín vuelve a San Giovanni in Fiore y es enterrado en la iglesia aún existente. El epitafio de su tumba reza: Hic Abbas Floris / caelestis gratiae roris. (Aquí yace el abad de Fiore / rociado por la gracia celestial).

El esquema histórico salvífico propuesto por Joaquín es bastante original en su época. Por otra parte, habiendo efectivamente recibido por gracia sus visiones iniciales, desarrolló su labor no con las características propias de aquella profecía que se obtiene mediante la ocupación de los órganos fonatorios o a través de la escritura empujada por la divinidad que se manifiesta, sino llevando a cabo una tarea exegética impulsado por el intellectus spiritualis que acciona en su esquema trinitario. La creencia de que las escrituras impliquen también la existencia de un sentido oculto, base de la exégesis joaquinita, es de larga data en la tradición. Ya Orígenes había desarrollado la idea de una interpretación de los escritos sagrados en tres instancias: literal, moral y alegórica. De igual manera, en el propio siglo XII, el de Joaquín, sus contemporáneos Ricardo y Hugo de San Víctor habían extraído tres niveles de conocimiento con sus respectivos sentidos. Así, la interpretación literal se da en la cogitatio (comprensión del mundo físico), la moral o psíquica se da en la meditatio (comprensión de la interioridad) y la alegórica o espiritual se da en la contemplatio (visión beatífica de Dios). ${ }^{5}$

Es probable que Joaquín haya conocido estas instancias interpretativas, tanto de Orígenes como de los victorinos. Su novedad y su mérito estriban en la transformación de estos tres niveles de secuencias instructivas y psicológicas en instancias históricas progresivas. Se trata del avance de la entera humanidad a través de tres edades sucesivas que en su trayecto van revelando la sabiduría divina. La tarea de Joaquín se centra por consiguiente en su labor interpretativa de las sagradas escri-

${ }^{5}$ Ernst Bloch, Hereditá del nostro tempo, trad. al italiano de Laura Boella (Milano: Arnaldo Mondadori Editore, 1992), 108. Traducción propia al castellano. 
turas, la revelación entregada por la Santísima Trinidad, y el curso de la historia en su paulatina revelación sacra.

Esa revelación progresiva, emanada de la doctrina de Joaquín, se manifiesta en tres edades, en las que una persona de la Trinidad prima en cada una de ellas. Así, el primer estado es el del Padre; el segundo, el del Hijo, y el tercero, aún por venir en el esquema joaquinita, es el del Espíritu Santo. De un modo especial, estos estados están comunicados y pueden solaparse, como se muestra visualmente en Il libro delle figure, ${ }^{6}$ de modo que es la Trinidad completa la que está siempre presente en cada estado. La persona correspondiente tiene cierta primacía, solamente, en cada uno de ellos.

Dejemos que sea el mismo Joaquín el que nos exponga su esquema de los tres estados o edades:

El primero de los tres estados de los que hablamos sucedió en el tiempo de la Ley cuando el pueblo del Señor servía por un tiempo como un niño pequeño bajo los elementos del mundo. No eran capaces todavía para alcanzar la libertad del Espíritu hasta que viniera el que dijo: "Si el Hijo los libera, en verdad seréis libres" (Juan, 8:66). El segundo estado sucedió bajo el Evangelio y permanece hasta el presente con libertad en comparación con el pasado pero no con libertad en comparación con el futuro. Porque el Apóstol dice: "Ahora conocemos en parte y profetizamos en parte, pero cuando aquel que es perfecto haya venido eso que es en parte será eliminado" (1 Corintios, 13:12). Y en otro lugar: "Donde el Espíritu del Señor esté, hay libertad" (2 Corintios, 3:17). Por lo tanto el tercer estado vendrá hacia el fin del mundo, ya no más bajo el velo de la letra, sólo en la completa libertad del Espíritu cuando después de la destrucción y de la cancelación del falso evangelio del Hijo de la Perdición y sus profetas, aquellos que les enseñarán a muchos acerca de la justicia serán como el esplendor del firmamento y como las estrellas por siempre. El primer estado que floreció bajo la Ley y la circuncisión comenzó con Adán. El segundo que floreció bajo el Evangelio comenzó con Uzziah. El tercero, en la medida en que podemos entender el

${ }^{6}$ Gioacchino da Fiore, Il libro delle figure II, ed. por Leone Tondelli, Marjorie Reeves y Beatrice Hirsch-Reich (Torino: Societá Editrice Internazionale, 1953), tavolas XI a y XI b. 
número de generaciones, comenzó en el tiempo de San Benito. $\mathrm{Su}$ sobresaliente excelencia debe ser esperada cerca del final, en el tiempo en que Elías será revelado y el no creyente pueblo judío se convertirá al Señor. En ese estado el Espíritu Santo parecerá proclamar en las Escrituras con su propia voz: "El Padre y el Hijo han trabajado hasta ahora; y yo estoy trabajando ahora". La letra del Primer Testamento parece por una cierta propiedad de semejanza pertenecer al Padre. La letra del Nuevo Testamento pertenece al Hijo. Así el entendimiento espiritual que procede de los dos pertenece al Espíritu Santo. Similarmente, el orden de los casados que floreció en el primer tiempo parece pertenecer al Padre por una propiedad de semejanza, el orden de los predicadores en el segundo tiempo al Hijo, y así el orden de los monjes a quienes los grandes últimos tiempos son dados pertenece al Espíritu Santo. De acuerdo con esto, el primer estado está adscrito al Padre, el segundo al Hijo, el tercero al Espíritu Santo, aunque por otra manera de hablar el estado del mundo debe decirse que es uno, el pueblo de los elegidos uno, y todas las cosas al mismo tiempo pertenecientes al Padre, Hijo y Espíritu Santo. Tampoco esto es pensado contrario a la autoridad de los Padres cuando ellos hablan del tiempo antes de la Ley, el tiempo bajo la Ley, y el tiempo bajo la Gracia. Cada uno se dice que es necesario en su propio modo. $^{7}$

El desarrollo de una historia progresiva se puede ver más concretamente a través de las formas éticas y sociales de las edades (Ernst Benz). Así, copiamos los estados en el Tratado sobre los cuatro evangelios:

El primero tiene la servidumbre de los esclavos, el segundo la servidumbre de los hijos, el tercero traerá la libertad.

El primero es uno de temor, el segundo de fe, el tercero de amor.

El primero es el período de los sirvientes, el segundo el de los hombres libres, el tercero de los amigos.

El primero es el período de los niños, el segundo de los hombres, el tercero de los ancianos.

7 "Exposición sobre el Apocalipsis", f. 5r-v, citado por Bernard McGinn, en Visions of the End. Apocalyptic Traditions in the Middle Ages (New York: Columbia University Press, 1979), 133-134. Traducción propia. 
El primero está iluminado por las estrellas, el segundo por la luz del amanecer, el tercero por el brillo del día.

El primero pertenece al invierno, el segundo a los primeros días de primavera, el tercero al verano.

El primero genera prímulas, el segundo rosas, el tercero lirios.

El primero genera pasto, el segundo tallos, el tercero espigas de trigo.

El primero trae agua, el segundo vino, el tercero aceite.

El primer período se relaciona con el Padre, el segundo con el Hijo, el tercero con el Espíritu Santo. ${ }^{8}$

La doctrina de las tres edades, de la que hemos tenido un asomo directo en lo recientemente leído, tiene como novedad para su época que los estadios respectivos están situados concretamente en el transcurso de la historia del mundo. En el último estadio, que corresponde al reino de la libertad, se encuentra en el momento final del transcurso histórico. En él se ha realizado progresivamente ese don liberador otorgado por Dios.

En los cálculos temporales hechos por Joaquín, a propósito del patrón de las generaciones que se conforma desde el pasado (no olvidemos como modelo la concordancia de número de generaciones entre el Antiguo y el Nuevo Testamento), la edad del Espíritu Santo debería tener inicio en el año 1260. Aparte de la inexactitud probada de tal fecha, lo central es consignar la importancia de las consecuencias que trae esta visión. En ella se hace presente que el propio tiempo de la Iglesia institucional acabará y que una nueva manera, que se podría denominar como una forma espiritual de iglesia, sin sacramentos, sin escritura correspondiente, con contacto directo con el Espíritu, con comunidad de contemplativos, con comunidad de bienes, entre otras características, tendría existencia. La opinión de Ernst Benz, a este respecto, viene a refrendar lo dicho y parece importante de mostrar. Dice:

En este cuadro, la historia de la salvación aparece, primero que nada, como una iluminación progresiva de la humanidad a través

${ }^{8}$ Benz, Evolution and Christian, 38-39. Traducción propia. A su vez, la traducción de Benz es de "Tractatus Super Quatuor Evangelia", de Joaquín de Fiore, publicado por Ernesto Buonaiuti en Fonti per la storia d'Italia, Scrittori sec. XII (Roma: 1930), 111, 7 ff. 
del medio de un siempre creciente conocimiento de salvación. La acción creativa del Espíritu Santo, que es la fuerza actuante en la historia de la salvación, tiene como finalidad el pasar a través de la intelligentia spiritualis que emergerá en forma pura durante el tercer período de salvación. ${ }^{9}$

Más adelante añade:

La validez de las Sagradas Escrituras y de los sacramentos está restringida al segundo período de salvación. Pierde su significación en el tercer período, cuando será reemplazada por la más alta comprensión de la salvación a través de la intelligentia spiritualis. ${ }^{10}$

Joaquín, hemos visto, caracterizaba al primer período como uno de servidumbre de esclavos; al segundo como el de la servidumbre de los hijos y al tercero como el de la libertad. Así, se puede entender que se manifiesta un proceso gradual de liberación. El período de la libertad, que es aquel de los "amigos de Dios", de los hombres espirituales, se da con la progresión de esa libertad otorgada por Dios en el estado del Espíritu Santo. Es preciso insistir que la vía que lleva de la inicial servitus legis (servidumbre de la ley) a la libertas amicorum (libertad de los amigos) ocurre en la historia universal.

Esta concepción da pábulo a diversas modalidades que han sido conectadas con la idea de revolución y de utopía. Así se manifiesta en la opinión de un filósofo marxista heterodoxo, Ernst Bloch, quien escribió un libro enciclopédico sobre el pensamiento utópico, El principio esperanza. La visión de Joaquín de Fiore es ocasión para Bloch de expresar el adelanto de una era que será la propia de la consumación utópica en nuestro propio tiempo secular. Nos dice respecto del abad: “Aquí está el atrevimiento específico de Joaquín: él ha orientado las miradas vueltas al más allá hacia un futuro terrestre y ha esperado su ideal no en el cielo, sino en la Tierra. Ha proclamado la libertad de los nuevos viri spirituales no como libertad del mundo, más bien para un nuevo mundo". ${ }^{11} \mathrm{Y}$ añade: "El Reino de Cristo es de este mundo, apenas este mundo sea

\footnotetext{
${ }^{9}$ Benz, Evolution and Christian, 41. Traducción propia.

${ }^{10} \mathrm{Ibí}$ dem, 41-42. Traducción propia.

${ }^{11}$ Bloch, Hereditá del nostro, 110. Traducción propia.
} 
nuevo". ${ }^{12}$ Continúa su idea de anticipación utópica en Joaquín resaltando la circunstancia en la que tal modo de pensar se ha podido desarrollar, al considerar lo siguiente: "El cristianismo, a partir de las circunstancias económicas que le ha signado el origen, se distingue en efecto de todas las otras religiones por haberse presentado desde el inicio como ideología de los oprimidos". ${ }^{13}$ Aun cuando esta característica podría verse como un acto de rebeldía, considerando el posterior desarrollo de la Iglesia institucional, nos dice, la idea joaquinita de la tercera edad ha permanecido, desde el momento en que pudo ser retomada por aquellos que la esperaban en el siglo XIII, como Gotthold Ephraim Lessing en $L a$ educación del género humano.

La concepción tripartita de Joaquín ha tenido persistencia y variada fortuna. La idea de las tres etapas se ha manifestado, por ejemplo, en la manera de periodizar la historia universal en antigua, medieval y moderna, llevada a cabo en el Renacimiento por Flavio Biondo. También Augusto Comte realizó una periodización semejante, al dividir la historia en una época teológica, luego una segunda metafísica, para concluir con una de ciencia positiva. Es conocida igualmente la mirada de Hegel, que divide la historia universal de acuerdo a tres niveles de libertad. Eric Voegelin los recuerda: “... la antigüedad con su despotismo oriental, cuando sólo uno era libre; luego los tiempos aristocráticos, cuando unos pocos eran libres; y ahora los tiempos modernos cuando todos son libres". ${ }^{14}$ Schelling, por su parte, distinguió tres etapas del cristianismo: la de Pedro, la de Pablo y la final de Juan, que concluirá la cristiandad perfecta. Asimismo, Marx y Engels hacen uso de la tripartición para indicar las fases de la historia como la primera de comunismo primitivo, la siguiente como de sociedad de clases de la burguesía, y la tercera y final de sociedad sin clases en la que el comunismo lleva al reino de la libertad. Estos constituyen algunos ejemplos de la tripartición, que seguramente podría seguir siendo mostrada en otros autores y modalidades.

Más que continuar en la puntualización del complejo y absorbente sistema de Joaquín de Fiore, que ciertamente podría prolongar cualquier

\footnotetext{
12 Ibídem. Traducción propia.

${ }^{13}$ Ibídem, 111. Traducción propia.

${ }^{14}$ Eric Voegelin, Science, Politics and Gnosticism. Two Essays (New York: Gateway Editions, 1964), 94. Traducción propia.
} 
escrito y cualquier meditación a trazos y lapsos considerables, creo conveniente cerrar este esbozo de su teoría con un conjunto de juicios críticos de algunos de los autores que me parece que son más autorizados para ello. En primer lugar, hago presente las palabras de Karl Mannheim, quien en su libro Ideología y utopía expresa:

En lo que se refiere a nuestro problema, el momento crítico y decisivo de la historia moderna fue aquél en el que el "quiliasmo" unió sus fuerzas a las exigencias activas de las capas oprimidas de la sociedad. La misma idea del advenimiento de un reinado milenario sobre la Tierra contuvo siempre una tendencia revolucionaria, y la Iglesia hizo toda clase de esfuerzos por paralizar esta idea, que trascendía la situación social, por todos los medios de los que pudo disponer. Estas doctrinas, renaciendo de modo intermitente, reaparecieron otra vez con Joaquín de Fiore, entre otros; pero, en su caso, ya no fueron, como antes, un pensamiento $\tan$ revolucionario. ${ }^{15}$

Otra opinión que me parece valiosa es la que procura un especialista en el tema: Henri Mottu, quien en su libro La manifestación del Espíritu según Joaquín de Fiore entrega lo siguiente:

Tal es la utopía de Joaquín: el Espíritu está por transformar el mundo; el Espíritu se vuelve el sujeto de todo su apocalipsis y el principio de todas sus esperanzas; la libertad espiritual se vuelca a la liberación total de todo lo que vinculaba, personas e instituciones, al pasado y a la crisis de la edad del Hijo. En este sentido, la utopía de Joaquín es progresiva. Pero la materia subjetiva de su utopía es ciertamente aún regresiva, puesto que no hace sino proyectar en el futuro su propio ideal eremítico. ${ }^{16}$

Es interesante la polarización entre progresión y regresión que hace presente Mottu. Yo no sé si en términos propuestos por otros pensadores la caracterización de Mottu de la visión de Joaquín calificaría

${ }^{15}$ Karl Mannheim, Ideología y utopía. Introducción a la sociología del conocimiento, trad. de Eloy Terron (Madrid: Aguilar, 1966), 282.

${ }^{16}$ Henri Mottu, La manifestazione dello spirito secondo Gioacchino da Fiore, trad. de Roberto Usseglio (Casale Monferrato: Casa Editrice Marietti, 1983), 282283. Traducción propia. 
como utópica. Una utopía regresiva es difícil de justificar, y alguien como Mannheim, que va directo a describir los tipos de utopía, no es convincente al referirse a uno de ellos: la utopía conservadora, la más cercana a la que podría ser considerada como regresiva.

Continuando con nuestro afán, hagamos presente el siguiente juicio de Karl Löwith, expresado en El sentido de la historia:

Esta consumación no ocurre más allá del tiempo histórico, al final del mundo, sino en la última etapa histórica. El esquema escatológico de Joaquín no consiste en un simple milenio, ni tampoco en una mera expectativa del fin del mundo, sino en un doble eschaton: una fase final histórica de la historia de la salvación, que precede al eschaton trascendente del nuevo eón, anunciada por la segunda venida de Cristo. El reino del Espíritu es la última revelación del designio de Dios sobre la Tierra y en el tiempo. ${ }^{17}$

Queda claro entonces lo que se manifestara con menos énfasis en el inicio de este escrito: lo que propone Joaquín no es un pensamiento milenario, al modo de aquellos que se basan en las palabras de Apocalipsis 20:3: "Lo arrojó al Abismo, lo encerró y puso encima los sellos, para que no seduzca más a las naciones hasta que se cumplan los mil años. Después tiene que ser soltado por poco tiempo". ${ }^{18}$ También debe citarse en el mismo capítulo el versículo 4 :

Luego vi unos tronos, y se sentaron en ellos, y se les dio el poder de juzgar; vi también las almas de los que fueron decapitados por el testimonio de Jesús y la Palabra de Dios, y a todos los que no adoraron a la Bestia ni a su imagen, y no aceptaron la marca en su frente o en su mano; revivieron y reinaron con Cristo mil años. ${ }^{19}$

Aun cuando Joaquín aceptaba la doctrina agustiniana que establecía las siete edades y mantenía un sentido escatológico en el que la aparición del Anticristo era inminente, no se puede hablar de una espera

${ }^{17}$ Karl Löwith, El sentido de la historia. Implicaciones teológicas de la filosofia de la historia, trad. de Justo Fernández Bujan (Madrid: Aguilar, 1958), 216-217.

${ }^{18}$ Biblia de Jerusalén (Bilbao: Desclée de Brouwer, 1975), 1785.

${ }^{19}$ Ibídem. 
pasiva del tiempo. Joaquín ubicaba la séptima edad, correspondiente al Sabbath de Agustín, no fuera del tiempo, como éste, sino como una edad dentro de la historia. Existe, como viéramos, un primer eschaton, con un Anticristo que pondrá fin a la sexta edad de San Agustín correspondiente a la segunda época de Joaquín, la del Hijo, y que dará curso a la séptima edad y que corresponde a la época del Espíritu Santo. Al final de este transcurso histórico en el Espíritu sobrevendrá el segundo momento del eschaton, y la venida de Cristo y el juicio final tendrán lugar.

En este punto, la conexión del sistema joaquinita con lo que hemos denominado el impulso utópico se da en la anticipación de una edad que se presiente plena y que activa al ser humano a considerar el futuro como posibilidad de transformación, en la cual él puede ser un factor que pone a esa edad en ejecución. Así lo entendieron los herederos del abad Joaquín de Fiore.

No se nos puede ocultar, por otro lado, que gran parte del impulso o del vigor del pensamiento utópico ha nacido de la secularización de las visiones escatológicas que enseñan un porvenir finalmente venturoso.

La escatología es parte esencial del cristianismo; constituye una categoría principal en la que el futuro y la esperanza se inician con fortaleza desde un presente que deja ver su inadecuación con respecto a las aspiraciones de lo humano. Así lo atestiguan las diversas teologías del genitivo, como se las ha llamado (de la esperanza, de la historia, de la liberación, entre otras), que tempranamente desde el siglo veinte se han ido desarrollando hasta la actualidad.

Termino esta exposición de índole escatológica y utópica con la visión que entrega un notable estudioso y especialista en el pensamiento utópico, Terry Eagleton, a propósito del trabajo del teólogo protestante Jurgen Moltmann. Dice Eagleton, siguiendo el tono del citado teólogo: "La esperanza nos mantiene en una posición radicalmente irreconciliable con el presente, por lo que constituye una fuente constante de desorden histórico". ${ }^{20}$ Tanto la escatología como la utopía se configuran en la dimensión afectiva de la esperanza.

${ }^{20}$ Terry Eagleton, Esperanza sin optimismo, trad. de Belén Urrutia (Buenos Aires: Taurus, 2016), 112. 


\section{BIBLIOGRAFÍA}

Benz, Ernst. Evolution and Christian Hope: Man's Concept of the Future from the Early Fathers to Teilhard de Chardin. New York: Doubleday and Company, 1966.

Biblia de Jerusalén. Bilbao: Desclée de Brouwer, 1975.

Bloch, Ernst. Hereditá del nostro tempo. Traducido por Laura Boella. Milano: Arnaldo Mondadori Editore, 1992.

Cohn, Norman. En pos del milenio. Revolucionarios milenaristas y anarquistas místicos de la Edad Media. Traducido por Ramón Alaix Busquets. Madrid: Alianza Universidad, 1985.

Eagleton, Terry. Esperanza sin optimismo. Traducido por Belén Urrutia. Buenos Aires: Taurus, 2016.

Fiore, Gioacchino da. Il libro delle figure II. Editado por Leone Tondelli, Marjorie Reeves, Beatrice Hirsch-Reich. Torino: Societá Editrice Internazionale, 1953.

Lessing, Gotthold E. La educación del género humano [1780]. En Escritos filosóficos y teológicos, traducido por A. Andreu Rodrigo. Madrid: Editora Nacional, 1982.

Löwith, Karl. El sentido de la historia. Implicaciones teológicas de la filosofía de la historia. Traducido por Justo Fernández Bujan. Madrid: Aguilar, 1958.

Mannheim, Karl. Ideología y utopía. Introducción a la sociología del conocimiento. Traducido por Eloy Terron. Madrid: Aguilar, 1966.

McGinn, Bernard. Visions of the End. Apocalyptic Traditions in the Middle Ages. New York: Columbia University Press, 1979.

Mottu, Henri. La manifestazione dello spirito secondo Gioacchino da Fiore. Traducción por Roberto Usseglio. Casale Monferrato: Casa Editrice Marietti, 1983.

Voegelin, Eric. Science, Politics and Gnosticism. Two Essays. New York: Gateway Editions, 1964. EP 